Article

\title{
On-Line Analysis of Oil-Dissolved Gas in Power Transformers Using Fourier Transform Infrared Spectrometry
}

\author{
Xiaojun Tang ${ }^{1, *}$, Wenjing Wang ${ }^{1}$, Xuliang Zhang ${ }^{1}$, Erzhen Wang ${ }^{1,2}$ and Xuanjiannan Li $^{1}$ \\ 1 State Key Laboratory of Electrical Insulation \& Power Equipment, Xi'an Jiaotong University, Xi'an 710049, \\ China; cathyyokou@stu.xjtu.edu.cn (W.W.); shalom_zhang@apple.com (X.Z.); \\ wezh_cq@petrochina.com.cn (E.W.); zhangyang@xihari.com (X.L.) \\ 2 State Engineering Laboratory of Low Permeability Oil and Gas Field Exploration and Development, \\ Xi'an 710018, China \\ * Correspondence: xiaojun_tang@xjtu.edu.cn; Tel.: +86-029-82665525
}

Received: 2 November 2018; Accepted: 14 November 2018; Published: 17 November 2018

check for updates

\begin{abstract}
To address the problem of on-line dissolved gas analysis (DGA) of a power transformer, a Fourier transform infrared (FT-IR) spectrometer was used to develop an analysis instrument. Carbon monoxide $(\mathrm{CO})$, carbon dioxide $\left(\mathrm{CO}_{2}\right)$, methane $\left(\mathrm{CH}_{4}\right)$, ethane $\left(\mathrm{C}_{2} \mathrm{H}_{6}\right)$, ethylene $\left(\mathrm{C}_{2} \mathrm{H}_{4}\right)$ and acetylene $\left(\mathrm{C}_{2} \mathrm{H}_{2}\right)$ were the analytes for the FT-IR spectrometer while propane $\left(\mathrm{C}_{3} \mathrm{H}_{8}\right)$, propylene $\left(\mathrm{C}_{3} \mathrm{H}_{6}\right)$, propyne $\left(\mathrm{C}_{3} \mathrm{H}_{4}\right)$, n-butane $\left(n-\mathrm{C}_{4} \mathrm{H}_{10}\right)$ and iso-butane (iso- $\left.\mathrm{C}_{4} \mathrm{H}_{10}\right)$ were the interferents, which might exist in the dissolved gas but are not currently used as analytes for detecting an internal fault. The instrument parameters and analysis approach are first introduced. Specifically, an absorption spectra reading approach by switching two cone-type gas cells into separate light-paths was presented for reducing the effects of gas in the gaps between gas cells and spectrometers, scanning the background spectrum without clearing the sample cell, and increasing the dynamics. Then, the instrument was tested with a standard gas mixture that was extracted from insulation oil in a power transformer. The testing results show that the detection limit of every analyte component is lower than $0.1 \mu \mathrm{L} / \mathrm{L}$, and the detection limits of all analytes meet the detection requirements of oil-dissolved gas analysis, which means that the FT-IR spectrometer may be an ideal instrument due to its benefits, such as being maintenance-free and having a high stability.
\end{abstract}

Keywords: oil-dissolved gas; power transformer; Fourier transform infrared spectrometer; gas chromatograph; spectral analysis

\section{Introduction}

Power transformers may be the most important piece of equipment in the operation of a power system and transmission network, or between lines of different voltage levels [1]. Thus, much attention is focused on the condition of transformers. According to IEC/IEEE standards [2,3], dissolved gas analysis (DGA) is commonly used to detect internal faults within power transformers during uninterrupted power services. The fault-related gases, which mainly include carbon monoxide $(\mathrm{CO})$, carbon dioxide $\left(\mathrm{CO}_{2}\right)$, hydrogen $\left(\mathrm{H}_{2}\right)$, methane $\left(\mathrm{CH}_{4}\right)$, ethane $\left(\mathrm{C}_{2} \mathrm{H}_{6}\right)$, ethylene $\left(\mathrm{C}_{2} \mathrm{H}_{4}\right)$ and acetylene $\left(\mathrm{C}_{2} \mathrm{H}_{2}\right)$, are used to assess the condition of the power transformer by analyzing their compositions, rates of generation and specific content ratios [1,4-7].

In accordance with the ASTM 3612 standard [8], gas dissolved in transformer oil is analyzed via gas chromatography (GC), which provides high measurement accuracy and repeatability. Using this method however, a DGA is usually performed only once a year due to various reasons, such as high 
costs, long running time and several standards that have to be applied to the extraction, storage, and transportation of oil samples to chemical laboratories [4]. Only when significant concentrations of fault gases are detected during routine transformer inspection is more frequent testing required. Therefore, DGA based on GC has many limitations.

To overcome the above problems, auto-GC for DGA on-line was developed and applied [5]. However, there are still many problems. First, the chromatographic column will be polluted by the analyzed gas after the GC has operated for a long time, leading to increasing inaccurate results until a calibration is performed again $[9,10]$. However, when the pollution is so serious that accuracy of the results cannot meet the requirements even after calibration, the chromatographic column must be replaced $[9,10]$. Second, the accuracy of the analysis results depends on the pressure of the carrier gas [11-13]. As the pressure decreases, the accuracy decreases, which means the gas pressure must be monitored. When the gas pressure is too low, the carrier gas must be supplied in time $[9,10]$. Therefore, both the calibration and gas supplement result in costly maintenance.

To avoid the problems associated with GC, further approaches for DGA have been presented based on spectroscopy because of their purported benefits, such as being maintenance-free, having no carrier gas requirement, etc. [14-16]. Bakar and Abu-Siada proposed a method to estimate the concentration of various dissolved gases in transformer oil using near infrared-to-infrared (NIR-IR) spectroscopy [4]. In addition, Benounis and his co-workers developed NIR and an optical fiber sensor for the detection of gases produced by transformation oil degradation [15]. We also attempted to analyze index gases dissolved in insulating oil using infrared spectroscopy [16].

However, the approaches above cannot solve the problem of long-term continued analysis. As a result, on-line techniques have been introduced. The Faraday Transformer Nursing Unit (TNU), produced by SYPROTEC, uses a Fourier transform infrared (FT-IR) spectrometer to detect $\mathrm{CO}, \mathrm{CO}_{2}$, $\mathrm{CH}_{4}, \mathrm{C}_{2} \mathrm{H}_{2}, \mathrm{C}_{2} \mathrm{H}_{6}, \mathrm{C}_{2} \mathrm{H}_{4}$ and $\mathrm{H}_{2} \mathrm{O}$, and a HYDRAN sensor to detect $\mathrm{H}_{2}$. Moreover, CoreSense ${ }^{\mathrm{TM}} \mathrm{M} 10$, another on-line form of DGA, produced by ABB, is also based on FT-IR, and can detect $\mathrm{H}_{2}, \mathrm{CH}_{4}$, $\mathrm{C}_{2} \mathrm{H}_{2}, \mathrm{C}_{2} \mathrm{H}_{4}, \mathrm{C}_{2} \mathrm{H}_{6}, \mathrm{CO}, \mathrm{CO}_{2}$, propane $\left(\mathrm{C}_{3} \mathrm{H}_{8}\right)$ and propylene $\left(\mathrm{C}_{3} \mathrm{H}_{6}\right)$. For both instruments, accuracy requirements can be met, but there are still some problems, such as instability. As a result, the Faraday DGA and CoreSense ${ }^{\mathrm{TM}} \mathrm{M} 10$ are not used widely in China and little information on them is available. The Southern Power Grid, one of the largest power grid companies in China, once imported a Faraday TNU, which was eventually discontinued due to its instability.

Later, in 2007, GE Energy produced the Kelman Transfix, a new on-line monitoring unit that measures individual dissolved gas based on the photoacoustic spectroscopy (PAS) technique. It is capable of automated multi-gas detection plus on-line moisture monitoring of eight gases, including $\mathrm{H}_{2}, \mathrm{CO}, \mathrm{CO}_{2}, \mathrm{CH}_{4}, \mathrm{C}_{2} \mathrm{H}_{2}, \mathrm{C}_{2} \mathrm{H}_{6}, \mathrm{C}_{2} \mathrm{H}_{4}$ and $\mathrm{H}_{2} \mathrm{O}$, and is able to provide DGA results every hour. Nevertheless, the PAS technique has limitations. On one hand, its accuracy may be affected by the absorption characteristics and the wave number range of the optical filters used in the detection $[17,18]$. On the other hand, although the accuracy is high (reportedly above $90 \%$ ) when detecting some organic gases, such as $\mathrm{CH}_{4}, \mathrm{C}_{2} \mathrm{H}_{2}, \mathrm{C}_{2} \mathrm{H}_{4}$, and $\mathrm{C}_{2} \mathrm{H}_{6}$, its accuracy in detecting $\mathrm{CO}$ and $\mathrm{CO}_{2}$ is low, especially with low concentrations of the dissolved gases [19].

To summarize, although the techniques of spectroscopy have many advantages, to the best of our knowledge, stability is always a problem for these instruments according to consumer's comments, which is exactly the aspect we focus on in this paper.

Infrared spectroscopy (IR) is believed to be the best method of green analytical chemistry [14]. It is a common approach for on-line gas analysis and is applied extensively in many fields, such as gas logging [20], environmental protection [21,22], mine safety [23], etc. Gases such as $\mathrm{CO}, \mathrm{CO}_{2}$, and organic gases including $\mathrm{CH}_{4}, \mathrm{C}_{2} \mathrm{H}_{2}, \mathrm{C}_{2} \mathrm{H}_{4}, \mathrm{C}_{2} \mathrm{H}_{6}, \mathrm{C}_{3} \mathrm{H}_{8}, \mathrm{C}_{3} \mathrm{H}_{6}$, propyne $\left(\mathrm{C}_{3} \mathrm{H}_{4}\right)$, n-butane $\left(n-\mathrm{C}_{4} \mathrm{H}_{10}\right)$, iso-butane (iso- $\left.\mathrm{C}_{4} \mathrm{H}_{10}\right)$, formaldehyde, and acetaldehyde can be traced accurately within the IR spectrum [24,25]. The concentration of each component of gases can also be determined with feature extraction methods, such as forward selection, neural networking, support vector machines (SVMs), Tikhonov regularization and partial least squares (PLS) regression [26,27]. Moreover, many papers 
have indicated the feasibility of developing a DGA based on FT-IR and conducted laboratory experiments [23,24]. However, results of testing equipment only meet specified requirements in the laboratory, which does not mean that on-site requirements can be met, since some practical issues and long-term performance have not been considered. Thus, several novel approaches have been put forward to reduce the limitations of IR absorption spectroscopy for DGA. The first issue is that the IR spectrum is incapable of tracing $\mathrm{H}_{2}$ [24]. To solve this problem and obtain all seven key gases dissolved in insulating oil, Bodzenta developed a special $\mathrm{H}_{2}$ sensor [28]. Furthermore, there are fault identification approaches based on six key gases [4]. In other words, some fault identification approaches based on the IR spectrum can be used without concentration information of $\mathrm{H}_{2}$. However, seven key gases were detected in the paper, using a special $\mathrm{H}_{2}$ sensor to detect the concentration of $\mathrm{H}_{2}$ and the IR spectrum to detect the concentration of the other six key gases. Second, the IR spectrum seems to be affected by water vapor, which can be easily solved using our previous work [23]. Third, baseline drift and even abnormal distortion is also common in the IR spectrum and is the key point affecting the long-term performance of the instrument. To solve this problem, a two-gas cell-switching method was first added in our work and was proven to be an effective method for reducing the effects arising from characteristic changes of components of the FT-IR spectrometer and from a concentration change in the gas in the gaps between the gas cell and FT-IR spectrometer. Fourth, the volume of the gas cell is often more than $100 \mathrm{~mL}$. To solve this problem, a cone-type gas cell was used first in our work, lowering the volume of gas needed for analysis to only $27 \mathrm{~mL}$ and leading to a successful fast response of dynamics. Moreover, $\mathrm{C}_{3}$ gases, including $\mathrm{C}_{3} \mathrm{H}_{8}, \mathrm{C}_{3} \mathrm{H}_{4}$ and $\mathrm{C}_{3} \mathrm{H}_{6}$, are considered in this paper. Since $\mathrm{C}_{3}$ gases can also be degassed from oil when a vacuum degasifier is used and their absorption spectra overlap with those of $\mathrm{CH}_{4}$ and $\mathrm{C}_{2} \mathrm{H}_{6}$, they will interfere with the analytes. If these gases are not taken as interferents when the gas analyzer is calibrated, a large error may affect analysis results of the analytes. In fact, some researchers have even suggested that $C_{3}$ gases might be the more appropriate index gases for predicting the internal fault of a power transformer because of their high solubility compared to the traditional dissolved-gases, which means less $C_{3}$ gases can escape from the oil [29].

In this paper, an on-line DGA instrument for power transformer fault detection based on an FT-IR spectrometer is developed. It contains the benefits of being maintenance-free, having no carrier gas requirement, and accurately tracing almost all the polar molecule gases. Both the structure of the instrument and the spectrometer parameters are given. Six gas components, including $\mathrm{CH}_{4}, \mathrm{C}_{2} \mathrm{H}_{6}$, $\mathrm{C}_{2} \mathrm{H}_{4}, \mathrm{C}_{2} \mathrm{H}_{2}, \mathrm{CO}$ and $\mathrm{CO}_{2}$, were taken as the analytes, while $\mathrm{C}_{3} \mathrm{H}_{8}$, iso- $\mathrm{C}_{4} \mathrm{H}_{10}, n-\mathrm{C}_{4} \mathrm{H}_{10}, \mathrm{C}_{3} \mathrm{H}_{4}$ and $\mathrm{C}_{3} \mathrm{H}_{6}$ were taken as interferents. Then, an analysis approach was introduced. Finally, the instrument was tested with standard gases and gas extracted from oil on-site.

\section{Methodology}

The performance of a DGA analyzer can be affected by its structure as well as the analysis approach due to several reasons. First, the DGA analyzer works continuously in a transformer substation, where the environmental temperature and pressure varies with time. Second, the detection limit of every analyte component is low. Third, there may be interferents in the gas mixture extracted from the oil. Since ethane has been extracted from insulating oil, it is possible that $\mathrm{C}_{3} \mathrm{H}_{8}, \mathrm{C}_{3} \mathrm{H}_{6}$, and even butane can also be extracted from the oil. Therefore, both the structure and analysis approach of the DGA analyzer must be set or chosen prudently.

\subsection{Instrument Structure and Parameters}

\subsubsection{Structure}

The schematic diagram of the oil-dissolved gas analyzer is shown in Figure 1. Twelve components were included: one FT-IR spectrometer, one storage cell, two gas cells and one switcher, one industrial computer, two temperature and pressure sensors, one adapter, one hydrogen sensor, one degassing 
unit, and one air conditioner. All components were assembled in a machine cabinet except for the air conditioner. The air conditioner was used to maintain the inside temperature of the machine cabinet at approximately $20^{\circ} \mathrm{C}$. The storage cell could provide power for the FT-IR spectrometer and the industrial computer in a loss-of-power event. Sensors were used to monitor the temperature and pressure of the analytes so that temperature and pressure compensation could be accounted for in the analysis results. The degassing unit was used to extract oil-dissolved gas from the insulation oil of the power transformer. Two gas cells, one called the background cell and the other called the working cell, are switched by the switcher, which is controlled by the industrial computer. Finally, the industrial computer was used to perform the spectrum analysis, read data such as the absorption spectrum and the outputs of sensors, and control the degassing unit and gas cell switcher. The outside and inside views of the oil-dissolved analyzer developed in this work are shown in Figure 2.

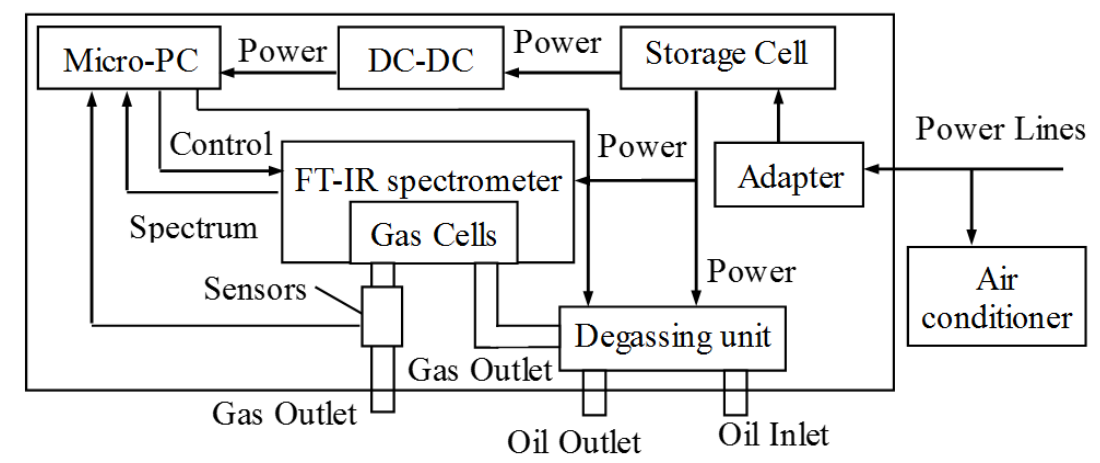

Figure 1. Schematic diagram of oil-dissolved gas analyzer.

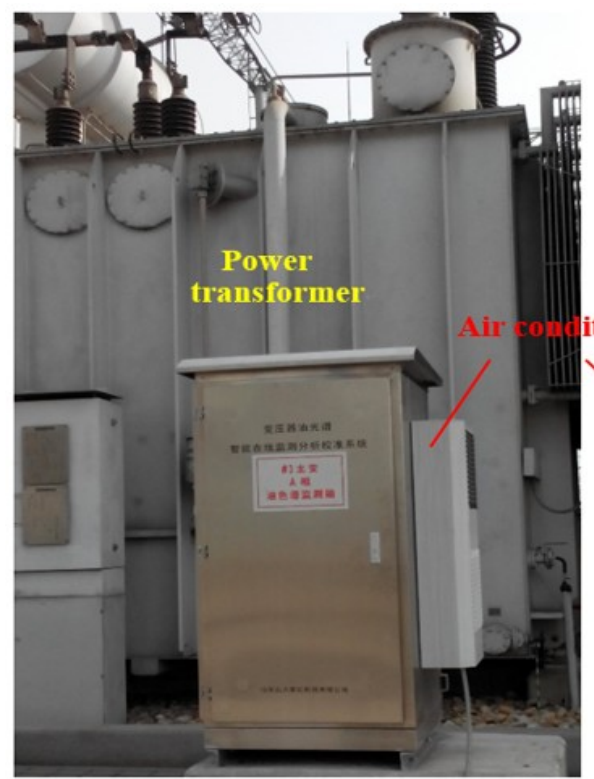

(a)

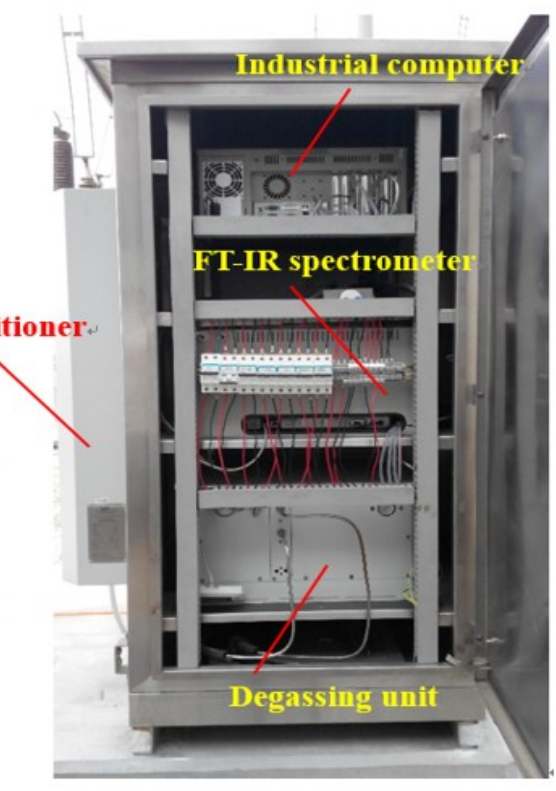

(b)

Figure 2. Outside view (a) and inside view (b) of the oil-dissolved gas analyzer.

\subsubsection{Parameters}

(1) FT-IR spectrometer

An IR Spectrometer named Spectrum Two, one type of FT-IR spectrometer developed by Perkin Elmer, was used in this work. Inside this spectrometer, a Globar light source was used as a mid-infrared source, while a standard deuterated triglycine sulfate (DTGS) detector was used to measure the full radiant power. The optical path was $10 \mathrm{~cm}$, the spectral resolution was set to $1 \mathrm{~cm}^{-1}$, and the 
wavenumber range was set to $400-4000 \mathrm{~cm}^{-1}$. The scanning time was set to 16 . In addition, the Norton-Beer medium function was selected as the apodization function, since it can lead to the best-fitting adherence to Beer's law for the spectra measured at a moderate resolution.

(2) Gas cell

For a common FT-IR spectrometer, the gas cell is tubular and requires a large amount of gas to fill. In this work, a different gas cell, fabricated in a two-cone shape as shown in Figure 3, was used to decrease the volume of gas needed. The diameter of the gas cell is $3 \mathrm{~cm}$ at the two sides while only $0.5 \mathrm{~cm}$ in the middle, with a volume of approximately $27 \mathrm{~mL}$. Because only a small amount gas can be separated from the $1000 \mathrm{~mL}$ of insulation oil [30], the gas cells used here could increase the dynamics of the analysis system.

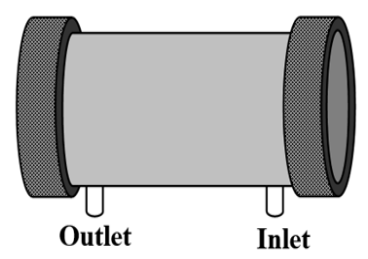

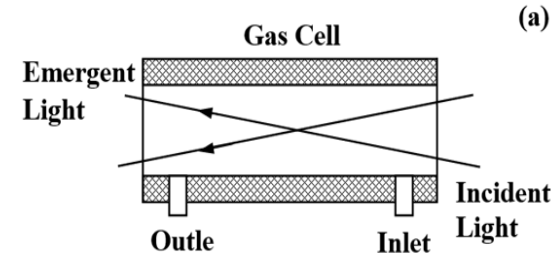

(b)

(a)

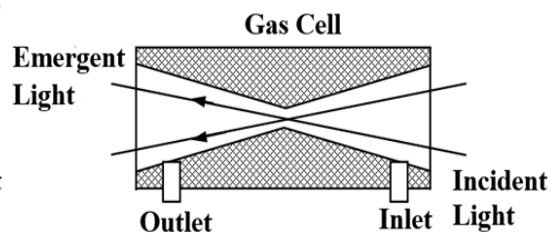

(c)

Figure 3. (a) Outside view of gas cell used in this work; (b) sectional drawing of pipe-type and light path; (c) sectional drawing of cone-type gas cell and light path.

(3) Temperature sensor and pressure sensor

The temperature and pressure of the analytes affect the volume percentage of the gas concentration. In this work, a BMP085 produced by Bosch was used to measure the temperature and pressure so compensation could be conducted to correct the analysis results during the process of spectrum scanning. This sensor could easily be assembled in the gas path due to its small size.

(4) Degassing unit

The degassing unit used here was a vacuum degasifier. There was a liquid flow-controller assembled at the oil inlet and a gas flow meter at the gas outlet. Under the control of the flow controller, $1000 \mathrm{~mL}$ of insulation oil was used to be degassed, which was later reinjected into the power transformer. The gas flow meter was used to measure the volume of oil-dissolved gas degassed from the insulation oil. With the vacuum degasifier, almost all of the dissolved gases (approximately $30 \mathrm{~mL}$ ) can be degassed from $1000 \mathrm{~mL}$ insulating oil [30]. The degassing procedure was introduced in [5].

\subsection{Analysis Approach}

The calibration process was identical to that performed in our previous work [23]. Two hundred sets of samples were prepared to calibrate the instrument. Among these samples, 30 sets were standard gases while the rest of the samples were mixtures of standard gases using a gas blending system based on gas flow controllers. The ambient temperature and pressure were maintained at $20^{\circ} \mathrm{C}$ and 760 Torr respectively during calibration. The gas-flow rate of the gas mixture flowing through the gas cell was kept at $1 \mathrm{~L} / \mathrm{min}$. The absorption spectra of 10 analyte and interferent components are shown in Figure 4, with a concentration of 1000 ppm. 


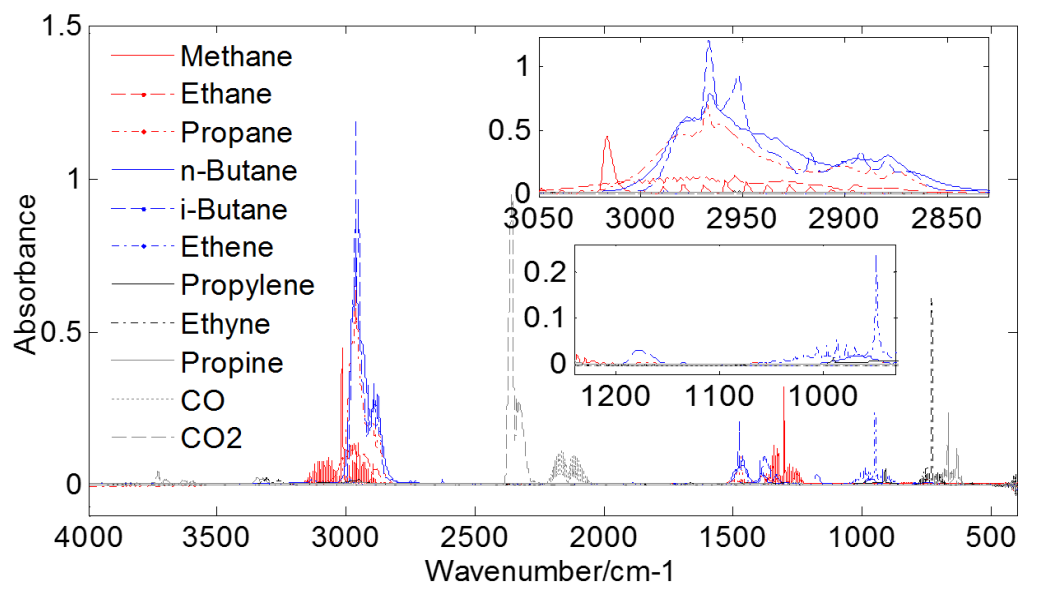

Figure 4. Absorption spectra of analytes and interferents with a concentration of $1000 \mathrm{ppm}$.

After obtaining the spectra of the samples, baseline corrections were first conducted. The correction approach used here is the piecewise two points auto-linear correlated correction method presented in our previous work [31]. Next, Tikhonov regularization and forward selection, two feature extraction methods, were respectively used for the two types of analyte components: components such as $\mathrm{C}_{2} \mathrm{H}_{2}, \mathrm{C}_{2} \mathrm{H}_{4}, \mathrm{C}_{3} \mathrm{H}_{6}, \mathrm{CO}$ and $\mathrm{CO}_{2}$, which have good selectivity, as shown in Figure 4, were extracted using forward selection; components whose absorption peaks overlap with others extensively, such as $\mathrm{CH}_{4}, \mathrm{C}_{2} \mathrm{H}_{6}$ and $\mathrm{C}_{3} \mathrm{H}_{8}$, were extracted using Tikhonov regularization [26].

The approaches for building the analysis models conducted here were also the same as in our previous work [23]. In brief, for the components whose feature variables have good linearity with the gas concentration, a multi-input linear analysis model was used; for the components whose feature variables have good selectivity, a polynomial model was used.

Differing from our previous work, the absorption spectrum of oil-dissolved gas was obtained according to the following procedures when the oil-dissolved gas analyzer works on-site.

(1) Before the analyzer was put into use, two gas cells, both injected with nitrogen, were scanned by the FT-IR spectrometer under the control of the gas cell switcher, which was switched into the light path. After scanning, two luminous intensity spectra were obtained. The one obtained with the background cell was denoted as $I_{b 0}$, and the other obtained with the working cell was denoted as $I_{m 0}$.

(2) After the analyzer was put into use, oil-dissolved gas was extracted from the insulation oil with a degassing unit under the control of an industrial computer and then was injected into a working cell while the background cell was maintained full of nitrogen.

(3) Two gas cells were scanned using the FT-IR spectrometer under the control of the gas cell switcher, which was switched into the light path once again. The luminous intensity spectrum obtained with the background cell was then denoted $I_{b 1}$, while that obtained with the working cell was denoted $I_{m 1}$.

(4) The absorbance spectrum $A$ of the oil-dissolved gas was calculated according to Equation (1):

$$
A=-\lg \left(\frac{I_{m 1}}{I_{m 0}}\right)+\lg \left(\frac{I_{b 1}}{I_{b 0}}\right)
$$

where $\lg (\cdot)$ is the common logarithm operator.

After the absorbance spectrum A was obtained, it was then analyzed with the software developed above, and the raw results were obtained. Here, the raw results are denoted $C_{\text {raw }}=\left[c_{1}, c_{2}, c_{3}, c_{4}, c_{5}\right.$, $\left.\mathrm{c}_{6}\right]^{\mathrm{T}}$, where the $\mathrm{c}_{1}, \mathrm{c}_{2}, \mathrm{c}_{3}, \mathrm{c}_{4}, \mathrm{c}_{5}$, and $\mathrm{c}_{6}$ are the concentrations of $\mathrm{CH}_{4}, \mathrm{C}_{2} \mathrm{H}_{6}, \mathrm{C}_{2} \mathrm{H}_{4}, \mathrm{C}_{2} \mathrm{H}_{2}, \mathrm{CO}$ and $\mathrm{CO}_{2}$, respectively. To reduce the effect resulting from the temperature and pressure, the analysis results of the oil-dissolved gas mixture were corrected by Equation (2): 


$$
C_{\text {correct }}=C_{\text {raw }} \times \frac{273+20}{273+T} \times \frac{P}{760}
$$

where $T$ is the temperature, in ${ }^{\circ} \mathrm{C}$, of the analyzed gas, $P$ denotes the pressure in Torr, and $C_{\text {correct }}$ is the corrected concentration vector of the analytes.

For a quantitative analysis of the gas mixture, the interferents must be taken into account. In oil-dissolved gas, there are water vapor and $\mathrm{H}_{2}$, in addition to the analytes listed above in the analyzed gas mixture, but no BTX (benzene, toluene, or xylene). For water vapor, as discussed in our previous work [18], it is easy to avoid the interference resulting from BTX of every analyte component because there is at least one absorption peak that does not overlap with the absorption regions of the vapor. $\mathrm{H}_{2}$ is a non-polar molecule and has no absorption peak in the infrared spectrum. Therefore, neither water vapor nor $\mathrm{H}_{2}$ will have any effect on the analysis of the analytes.

\section{Testing Results and Analysis}

\subsection{Testing Results with Standard Gases}

According to IEC 60567 [32], the sensitivity requirements of a DGA analyzer are specified for factory acceptance tests and for equipment in service, as listed in Table 1 [5].

Table 1. Sensitivity requirements of a dissolved gas analysis (DGA) analyzer.

\begin{tabular}{ccc}
\hline \multirow{2}{*}{ Gases } & \multicolumn{2}{c}{ Detection Limits/( $\mu \mathrm{L} / \mathrm{L})$} \\
\cline { 2 - 3 } & Factory Acceptance Tests & Equipment in Service \\
\hline $\mathrm{H}_{2}$ & 2 & 5 \\
Hydrocarbons & 0.1 & 1 \\
$\mathrm{CO}$ & 5.0 & 25 \\
$\mathrm{CO}_{2}$ & 10 & 25 \\
Atmospheric gases & 50 & 50 \\
\hline
\end{tabular}

In our previous work [23], the detection limit and precision of every analyte component are given. In this paper, the testing experiments were performed again. With approximately $30 \mathrm{~mL}$ of gas being degassed from $1000 \mathrm{~mL}$ of oil [30], the detection limit and precision can be transformed into that for the dissolved gas analysis by multiplying them by 0.03 . Although the approach for obtaining the absorption spectra here was different from that used before, the testing results obtained with the standard gases are almost the same since the transmittance is the ratio of luminous intensity measured by the detector.

By comparing Tables 1 and 2, it can be seen that the maximum error of every component is lower than the corresponding detection limit of the factory acceptance tests when the concentration is very low.

Table 2. Root mean square of the analyte and maximal analysis error in the case of background spectra (L/L).

\begin{tabular}{cccccccc}
\hline Item & Gas & $\begin{array}{c}\text { Root Mean } \\
\text { Square }\end{array}$ & $\begin{array}{c}\text { Maximal } \\
\text { Error }\end{array}$ & Item & Gas & $\begin{array}{c}\text { Root Mean } \\
\text { Square }\end{array}$ & $\begin{array}{c}\text { Maximal } \\
\text { Error }\end{array}$ \\
\hline 1 & $\mathrm{CH}_{4}$ & 0.015 & 0.026 & 7 & $\mathrm{C}_{3} \mathrm{H}_{6}$ & 0.031 & 0.057 \\
2 & $\mathrm{C}_{2} \mathrm{H}_{6}$ & 0.008 & 0.034 & 8 & $\mathrm{C}_{2} \mathrm{H}_{2}$ & 0.005 & 0.009 \\
3 & $\mathrm{C}_{3} \mathrm{H}_{8}$ & 0.031 & 0.057 & 9 & $\mathrm{C}_{3} \mathrm{H}_{4}$ & 0.036 & 0.068 \\
4 & $\mathrm{iso}_{4} \mathrm{C}_{4} \mathrm{H}_{10}$ & 0.012 & 0.024 & 10 & $\mathrm{CO}$ & 0.018 & 0.057 \\
5 & $n-\mathrm{C}_{4} \mathrm{H}_{10}$ & 0.031 & 0.054 & 11 & $\mathrm{CO}_{2}$ & 0.012 & 0.032 \\
6 & $\mathrm{C}_{2} \mathrm{H}_{4}$ & 0.015 & 0.033 & - & - & - & - \\
\hline
\end{tabular}

The analysis error of every analyte component in different concentrations can also be obtained from our previous work, with the testing results shown in Table 3 [23]. This table indicates that the 
maximum error is less than $0.6 \mu \mathrm{L} / \mathrm{L}$ when the component concentration is lower than $3 \mu \mathrm{L} / \mathrm{L}$. Thus, it is less than $1 \mu \mathrm{L} / \mathrm{L}$, meeting the requirement of the detection limit of equipment in service, as shown in Table 1. Since the testing results were obtained with a mixed gas where all $C_{3}$ and $C_{4}$ gases, with the exception of the common analyte in the gas, were present and extracted from power transformer oil, it can be concluded that this equipment still meets the detection limit requirement of IEC 60567 even when it is in service.

Table 3. Maximum testing error or relative error within different concentration range.

\begin{tabular}{cccccc}
\hline Item & $\begin{array}{c}\text { Concentration } \\
\text { Range/ }(\mu \mathrm{L} / \mathrm{L})\end{array}$ & $\begin{array}{c}\text { Maximum } \\
\text { Error/ }(\mu \mathrm{L} / \mathrm{L}) \text { or } \\
\text { Relative Error }\end{array}$ & Item & $\begin{array}{c}\text { Concentration } \\
\text { Range/ }(\mu \mathrm{L} / \mathrm{L})\end{array}$ & $\begin{array}{c}\text { Maximum } \\
\text { Error/ }(\mu \mathrm{L} / \mathrm{L}) \text { or } \\
\text { Relative Error }\end{array}$ \\
\hline 1 & $\leq 0.3$ & $0.18 \%$ & 4 & $30-300$ & $4.7 \%$ \\
2 & $0.3-3$ & $0.6 \%$ & 5 & $300-3000$ & $3.5 \%$ \\
3 & $3-30$ & $9.5 \%$ & 6 & $\geq 3000$ & $2.2 \%$ \\
\hline
\end{tabular}

Additionally, there is evidence that $\mathrm{C}_{3}$ gases, including $\mathrm{C}_{3} \mathrm{H}_{8}, \mathrm{C}_{3} \mathrm{H}_{6}$ and $\mathrm{C}_{3} \mathrm{H}_{4}$, have been detected, and they may be the more appropriate index gases for predicting an internal fault of a power transformer [29]. Since the concentration of $C_{3}$ gases could be obtained, as listed in Table 2, the analyzer developed in this work is a better alternative instrument than GC, with respect to $C_{3}$ gases, when needed for a fault forecast without additional cost.

\subsection{Testing Results On-Site}

The DGA analyzer developed in this work was put into use on-site at a transformer substation on 19 January 2016 for further testing. The transformer substation is located in Laiwu City, China. The oil-dissolved gas absorption spectra were scanned with two gas cells and calculated using two methods. One method is the approach presented in this work, calculated by Equation (1), while the other is the common method, calculated by Equation (3):

$$
A=-\lg \left(\frac{I_{m 1}}{I_{m 0}}\right)
$$

Specifically, in both methods $I_{m 0}$ represents the luminous spectra scanned with a working gas cell full of nitrogen, while $I_{m 1}$ represents the luminous spectra scanned with a working gas cell after the DGA analyzer has been put into use. $I_{b 0}$ refers to the luminous spectra scanned with the background cell full of nitrogen, while $I_{b 1}$ was scanned with the background gas cell just before $I_{m 1}$ was scanned.

Both spectra, calculated in different ways, were scanned for each day. The spectra are shown in Figures 5 and 6, respectively.

In Figures 5 and 6, "Jan 19", "Feb 16" and "Mar 06" mean that $I_{m 1}$ and $I_{b 1}$ were obtained at 8:00 p.m. on 19 January 2016, 16 February 2016 and 06 March 2016, respectively, while the background luminous intensity spectra $I_{b 0}$ and $I_{m 0}$ were obtained at 8:00 a.m. on 19 January 2016.

From Figure 5, it can be seen that the baseline of "Jan 19" is almost a line at a value of 0, whereas there seems to be absorption peaks at $1100 \mathrm{~cm}^{-1}$ for "Feb 16" and "Mar 06". There are, however, no absorption peaks for every analyte and interferent component near $1100 \mathrm{~cm}^{-1}$, as is shown in Figure 4. At the same time, the baselines of the three spectra shown in Figure 6 are all almost horizontal lines. In other words, distortion occurs in the absorption baseline of "Feb 16" and "Mar 06" shown in Figure 5 but not in Figure 6. As a result, the approach presented in this work can reduce the baseline distortion of the gas absorption spectrum and avoid the error in the analysis results due to baseline distortion [31]. 


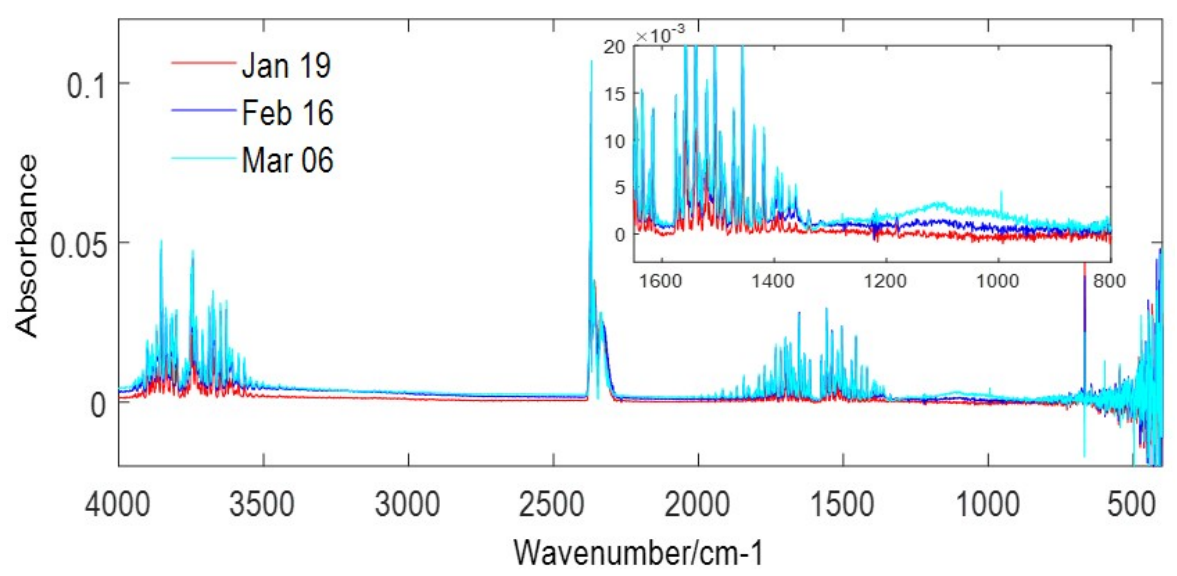

Figure 5. Absorption spectra of oil-dissolved gas obtained using the common method, i.e., $A=-\lg \left(I_{m 1} / I_{m 0}\right)$ with the DGA analyzer developed based on a Fourier transform infrared (FT-IR) spectrometer. $I_{m 0}$ means the luminous spectra were scanned with a working gas cell full of nitrogen. It was scanned on 19 January 2016. $I_{m 1}$ means the luminous spectra were scanned with the working gas cell after DGA analyzer was put into use. The absorbances denoted with "Jan 19", "Feb 16" and "Mar 06" mean that $I_{m 1}$ was scanned on 19 January 2016, 16 February 2016 and 06 March 2016, respectively.

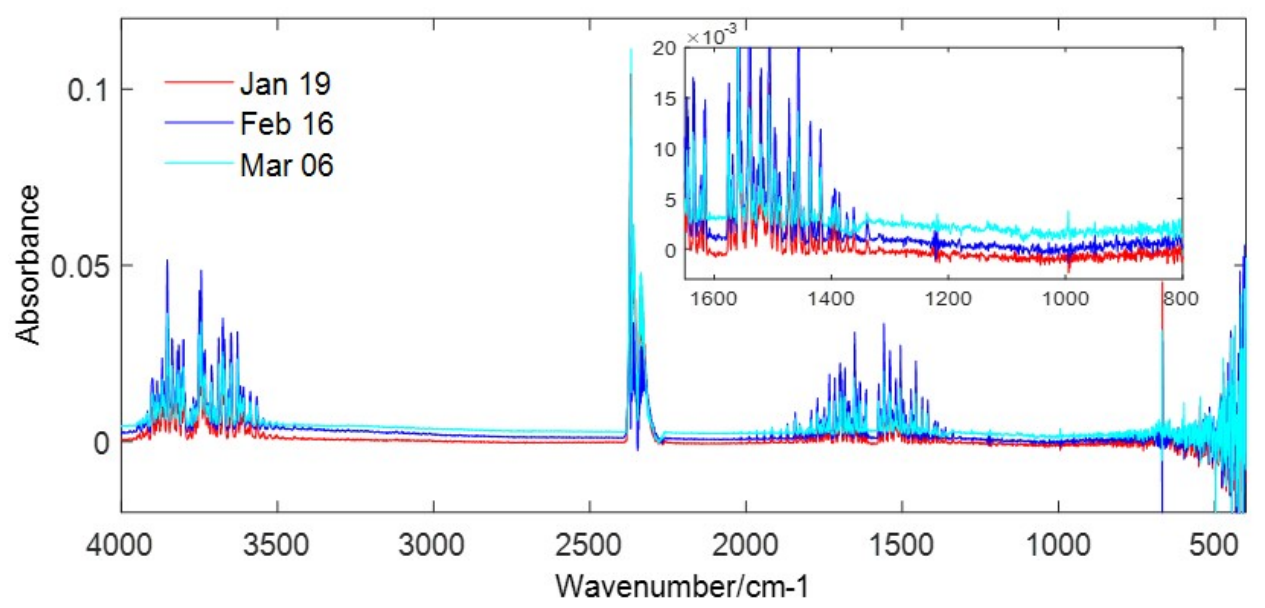

Figure 6. Absorption spectra calculated with the luminous intensity spectra according to $A=-\lg \left(I_{m 1} / I_{m 0}\right)+\lg \left(I_{b 1} / I_{b 0}\right) . I_{m 0}$ and $I_{m 1}$ are the same as used in Figure $5 . I_{b 0}$ means the luminous spectra were scanned with background cell full of nitrogen. $I_{b 1}$ was scanned with the background gas cell just before $I_{m 1}$ was scanned on the same day.

It can also be seen that absorbance of "Mar 06" and of "Feb 16" are higher than that of "Jan 19" in both Figures 5 and 6 within the high wavenumber band, which means that there still exists a little baseline drift in both Figures 5 and 6. This drift is normally caused by an alignment of the interferometer in the FT-IR spectrometer [33]. However, this is not a significant issue for gas analysis since a drifted baseline can be corrected via a baseline correction afterwards [31].

From the subfigure in Figure 5, it is obvious that the peak height of "Mar 06" is higher than that of "Feb 16" in the wavenumber band from $1430 \mathrm{~cm}^{-1}$ to $1580 \mathrm{~cm}^{-1}$, which is one of the absorption bands of water vapor. However, in Figure 6, the situation is the inverse. This case may be caused by the difference in concentrations of water vapor in the gaps between the gas cell and FT-IR spectrometer, which is due to the atmosphere. Normally, weather changes slowly, so the concentration of water vapor in the gaps when $I_{m 1}$ was scanned was considered the same as that when $I_{b 1}$ was scanned because the time difference of the two procedures was approximately $8 \mathrm{~min}$. Similarly, the concentration of water vapor when $I_{m 0}$ was scanned was also the same as that when $I_{b 0}$ was scanned. However, 
the concentration of water vapor when $I_{m 1}$ was scanned might differ from that when $I_{m 0}$ was scanned due to the long time difference and change in weather. In fact, the weather on both 06 March 2016 and 16 February 2016 was cloudy. However, the temperature on 06 March 2016 was $5-10^{\circ} \mathrm{C}$ whereas that on 16 February 2016 was $-3-5^{\circ} \mathrm{C}$. Additionally, the humidity level of the atmosphere on 16 February was lower than that on 6 March due to the concretion of water vapor. This is the reason why the absorption peak of water vapor for "Mar 6" is higher than that for "Feb 16". Additionally, by comparing the height of the absorbance of water vapor shown in Figure 6 and that of methane shown in Figure 5, it can be concluded that the absorption spectrum of water vapor has a high sensitivity. Not only is the approach for scanning the gas absorption spectrum presented in this work able to reduce the error brought from gases in gaps, but water vapor can also be analyzed accurately if a calibration was properly performed. Consequently, the approach for scanning the gas absorption spectrum presented in this work can also avoid the adverse impact arising from gas in the gaps between the gas cell and FT-IR spectrometer, especially for water vapor.

The analysis results of the spectra shown in Figures 5 and 6 are shown in Table 4. "Single" here is used to denote the analysis results in Figure 5 since the spectra shown in Figure 5 were obtained with only one gas cell. Similarly, "Double" denotes what is shown in Figure 6. From this table, it can be seen that the concentrations of all analytes are less than the detection limit listed in IEC 60567, except for $\mathrm{CO}_{2}$. In fact, the concentration of $\mathrm{CO}_{2}$ is far away from the fault point, which means that the power transformer is in a good state. Additionally, it can also be seen that the concentration of $\mathrm{C}_{2} \mathrm{H}_{4}$ denoted with "Single" is always less than that denoted with "Double". At the same time, the concentration of $\mathrm{CO}_{2}$ denoted with "Single" is always larger than that denoted with "Double". This difference may be caused by the baseline distortion. On 16 February 2016, we took a tube of oil from this power transformer and analyzed it with GC in a laboratory. The concentrations of the analytes are listed in Table 4. Results were almost the same as those from testing on-site. Thus, we can infer that the on-site analysis results meet the requirement of the DGA standard.

Table 4. Analysis results on-site (L/L).

\begin{tabular}{cccccccc}
\hline Date & & $\mathbf{C H}_{\mathbf{4}}$ & $\mathbf{C}_{\mathbf{2}} \mathbf{H}_{\mathbf{6}}$ & $\mathbf{C}_{\mathbf{2}} \mathbf{H}_{\mathbf{4}}$ & $\mathbf{C}_{\mathbf{2}} \mathbf{H}_{\mathbf{2}}$ & $\mathbf{C O}$ & $\mathbf{C O}_{\mathbf{2}}$ \\
\hline \multirow{2}{*}{ 19 January } & Single & 0.0384 & 0 & 0.1745 & 0 & 0 & 51.73 \\
& Double & 0.0187 & 0 & 0.2772 & 0 & 0.061 & 39.78 \\
& Single & 0.0011 & 0 & 0.4214 & 0 & 0 & 71.16 \\
16 February & Double & 0 & 0.0214 & 0.4476 & 0 & 0.048 & 68.13 \\
& Single & 0.1353 & 0 & 0.4749 & 0 & 0.032 & 79.68 \\
GC March in Lab & Double & 0.0888 & 0.0282 & 0.519 & 0 & 0 & 50.55 \\
& & 0.11 & 0.01 & 0.42 & 0 & 0.02 & 50.03 \\
\hline
\end{tabular}

\subsection{Dynamics}

The dynamics is an important index for DGA analyzer. A high response indicates that a fault can be found in time. In this work, the dynamics can be represented by the spectra scanned continuously just after the analyzer was put into use, as shown in Figure 7. In Figure 7, "data $i$ " means the $i$ th spectrum. From this figure, it is easy to see that the absorption peak height of water vapor of "data4" is almost the same as that of "data3", which means that three times the amount of degassing can put the degassing process into a stable state. As noted above, the DGA is usually performed once a year [4]. Therefore, the DGA analyzer of this paper can easily meet the requirements, and the frequency of testing can be set higher if any suspicious failure occurs.

The fast response is due to the structure of the gas cell shown in Figure 3. As introduced above, the diameter of the gas cell is $3 \mathrm{~cm}$ at the two sides while $0.5 \mathrm{~cm}$ at the middle, and the length of the gas cell is $10 \mathrm{~cm}$. As a result, the volume is around one-third of the cylinder-shape design, whose volume is $70.68 \mathrm{~mL}$. The reason that the gas call structure can be used here is that the light path resembles two tip-to-tip cones used in a commercial FT-IR spectrometer [33]. 


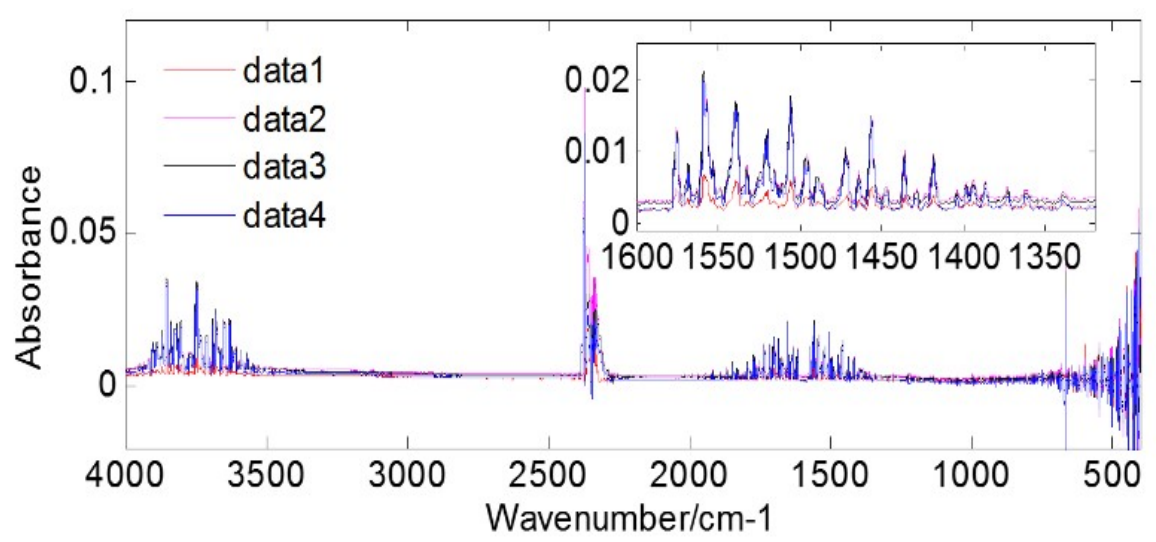

Figure 7. Spectra scanned continuously just after the analyzer was put into use. "data $i$ " means the $i$ th spectrum. The absorption peak height of water vapor of "data4" is almost the same of that "data3", which means that only three times the amount of degassing can put the degassing process into stable state.

The procedure from the very beginning to the stable state is analyzed as follows. Once degassing had been performed, the gas was injected through the inlet. At the same time, the gas in the gas cell was vented. As noted earlier, the volume of the gas cell is approximately $27 \mathrm{~mL}$ while the volume of the gas is approximately $30 \mathrm{~mL}$. If the degassed gas is mixed with the $27 \mathrm{~mL}$ gas that was in the gas cell, the concentration of every component in the mixture would be approximately 0.53 times that of the component in the degassed gas after the first mixing was performed. The analytes, however, could not spread to the outlet immediately when the degassed gas was injected into the gas cell. Thus, the concentration of analytes in the vent gas is always lower than the average concentration in the gas cell during the injection procedure. Specifically, the concentration of analytes was lower by 0.53 times than that in the degassed gas after the first mixing. After the second mixing, it increased to be higher by $80.3 \%$, and then increased to be higher by $95 \%$ after the third mixing.

\subsection{Stability}

As discussed in the introduction, the stability of a gas analyzer developed with an FT-IR spectrometer suffers from interferents, baseline drift and abnormal distortion. For the former, some gases such as $\mathrm{C}_{3} \mathrm{H}_{8}, \mathrm{C}_{3} \mathrm{H}_{6}$ that can be degassed from oil have been taken into account during the process of calibration. The main source of instability is baseline distortion. In order to quantify the stability of the setup used in this paper, a Fourier transform was performed with baseline correction and feature variable extracted. This method has ever been used to identify the baseline distortion of absorption spectrum of gas in our previous work [34].

First, the spectral baseline reading from the spectrometer was corrected with the common approach [31] followed by standard gas analysis. Then, absorbance of analytes was reconstructed and reduced from the corrected spectrum. Finally, Fourier transform was performed with the difference spectrum, and the first four-line strengths were used as feature variables according to Equation (4).

$$
v=f_{2}+f_{3}+f_{4}-\left(f_{5}+f_{6}+f_{7}\right)
$$

where $v$ is the dimensionless feature variable, and $f_{i}$ denotes the $i$ th line strength of the Fourier transform spectrum of difference spectrum.

When the method introduced in this subsection is performed for the wavenumber range from $700-1300 \mathrm{~cm}^{-1}$ of the spectra shown in Figures 5 and 6, the feature variables shown in Table 5 can be obtained. From Table 5, it can be found that all the feature variables of the spectra shown in Figure 6 are almost the same as that of "Jan 19" shown in Figure 5 while that of "Feb 16" and "Mar 06" shown in Figure 5 double and redouble. Since this feature variable indicates baseline stability, the lower the 
feature variable, the more stable the spectrum baseline. Thus, the low values of the feature variables of the spectra shown in Figure 6 show that the method of reading spectra presented in this paper has high stability. It is at least more stable than the common method of reading spectra with only one gas cell. In fact, during the past two years, the feature variables of the spectra read with the method presented in this paper are less than 1.05. We believe this method may remain an effective means of obtaining stable absorption spectra of oil-dissolved-gas for some time. On the other hand, the typical lifetime of a commercial FT-IR spectrometer is several years, and perhaps more than ten years, when in continuous use. The setup described in this paper may have long-term stability.

Table 5. Feature variables of spectrum shown in Figures 5 and 6.

\begin{tabular}{ccc}
\hline \multirow{2}{*}{ Spectrum Name } & \multicolumn{2}{c}{ Feature Variable } \\
\cline { 2 - 3 } & Figure 5 & Figure 6 \\
\hline Jan 19 & 0.0968 & 0.0983 \\
Feb 16 & 0.1842 & 0.0996 \\
Mar 06 & 0.3671 & 0.0989 \\
\hline
\end{tabular}

\section{Discussion}

Many experiments have been conducted in previous papers to verify that DGA-based FT-IR can detect fault gases accurately [35,36], but conditions are different when applied to on-site testing. There are some problems that should be considered.

First, interferents such as $\mathrm{C}_{3} \mathrm{H}_{8}$ and $\mathrm{C}_{3} \mathrm{H}_{6}$, which may exist in the gas degassed from oil and can affect analysis accuracy, have not been considered in these papers.

Second, the gas cells used in laboratories are common tube gas cells, whose volume is far more than $30 \mathrm{~mL}$, although approximately $30 \mathrm{~mL}$ of gases can be degassed from $1000 \mathrm{~mL}$ of insulating oil [30].

Third, long-term performance is the key point for on-line DGA, and is dependent mainly on the existence of baseline drift and abnormal distortion, and the presence of interferents. Experiments conducted in a laboratory cannot reflect on-site long-term performance. Moreover, the existing DGA methods based on FT-IR, such as the Faraday DGA and CoreSense ${ }^{\mathrm{TM}}$ M10, are not used widely in China. We understand that Southern Power Grid, one of two big electrical power companies in China, once imported a Faraday TNU but eventually discontinued it due to its instability.

To date, the DGA developed in the paper has worked when applied to the National Grid of China for a significant period, without any loss of accuracy. Thus, it is believed that the method's long-term performance is good. This instrument is now listed in the popularization program of South Power Grid in China.

The DGA analyzer designed in this paper can be improved and have a wider use. For example, there may be other interferents, such as formaldehyde gas or a component of furfural, in the oil-dissolved gases, which can also be used to predict internal faults of a power transformer [29,37]. According to the high-resolution transmission molecular absorption (HITRAN) database [24] and the National Institute of Standards and Technology (NIST) Atomic Spectra Database [25], gases such as formaldehyde, acetaldehyde and methylbenzene have absorption spectrum within the IR spectrum. In addition, the FT-IR spectrum has already been used to detect concentrations of formaldehyde gas [38]. Consequently, our next work will develop a new type of analyzer, which can give concentrations of $C_{3}$ and other organic gases, such as formaldehyde gas.

\section{Conclusions}

In this work, an FT-IR spectrometer was used to build a DGA analyzer that was put into use for analyzing oil-dissolved gas on-line and on-site. According to the testing results obtained with standard gases and gases extracted from the insulation oil, the following conclusions can be drawn. 
First, besides the many advantages of FT-IR, such as having no carrier gas, being maintenance-free, having high stability and accurate tracing for almost all organic gases, etc., this work may be a progression for on-line oil-dissolved gas monitoring since the accuracy of the DGA based on the FT-IR spectrometer meets the requirements of IEC 60567. Additionally, it is possible to analyze $C_{3}$ gases using the analyzer developed in this work.

Second, a new approach for reading the absorption spectra is put forward to ensure the long-term performance of the instrument. With two gas cells switching, this new approach can remove the effects arising from characteristic changes of components of the FT-IR spectrometer and from concentration changes of the gas in the gaps between the gas cell and the FT-IR spectrometer. This may be one of the highlights for obtaining stable analysis results on-line.

Third, the volume of the cone-type gas cell is less than $1 / 2$ that of a tubular gas cell. This design improves the dynamics of gas measurement on-line, especially when the volume of the degassed gas is small.

Finally, an FT-IR spectrometer can also be used to analyze water vapor on-line if a relative calibration is performed since the absorption spectra of water vapor is stable and has high sensitivity.

Author Contributions: Conceptualization, X.T.; methodology, X.T. and X.L.; software, X.Z. and W.W.; formal analysis, E.W.; investigation, X.T.; writing-original draft preparation, X.T.; writing-review and editing, W.W.; supervision, X.Z.; funding acquisition, X.T.

Funding: This research was funded by the General Program of National Natural Science Foundation of China (51277144) and the National Key Research and Development Program of China (2016YFF0102805).

Conflicts of Interest: The authors declare no conflict of interest. The sponsors had no role in the design, execution, interpretation, or writing of the study.

\section{References}

1. De Faria, H., Jr.; Costa, J.G.S.; Olivas, J.L.M. A review of monitoring methods for predictive maintenance of electric power transformers based on dissolved gas analysis. Renew. Sustain. Energy Rev. 2015, 46, 201-209. [CrossRef]

2. International Electrotechnical Commission. Mineral Oil-Impregnated Electrical Equipment in Service-Guide to the Interpretation of Dissolved and Free Gases Analysis; IEC 60599; International Electrotechnical Commission (IEC): Geneva, Switzerland, 1999.

3. Transformers Committee. Guide for the Interpretation of Gases Generated in Oil-Immersed Transformers; IEEE Std C57.104; IEEE: New York, NY, USA, 1991.

4. Bakar, N.A.; Abu-Siada, A. A New Method to Detect Dissolved Gases in Transformer Oil using NIR-IR Spectroscopy. IEEE Trans. Dielectr. Electr. Insul. 2017, 24, 409-419. [CrossRef]

5. Arakelian, V.G. The Long Way to the Automatic Chromatographic Analysis of Gases Dissolved in Insulating Oil. IEEE Electr. Insul. Mag. 2004, 20, 8-25. [CrossRef]

6. Godina, R.; Rodrigues, E.M.; Matias, J.C.; Catalão, J.P. Effect of Loads and Other Key Factors on Oil-Transformer Ageing: Sustainability Benefits and Challenges. Energies 2015, 8, 12147-12186. [CrossRef]

7. Chen, W.; Chen, X.; Peng, S.; Li, J. Canonical Correlation Between Partial Discharges and Gas Formation in Transformer Oil Paper Insulation. Energies 2012, 5, 1081-1097. [CrossRef]

8. ASTM 3612. Standard Test Method for Analysis of Gases Dissolved in Electrical Insulating Oil by Gas Chromatography; ASTM International: West Conshohocken, PA, USA, 2009.

9. McNair, H.M.; Bonelli, E.J. Basic Gas Chromatography; Wiley: Hoboken, NJ, USA, 1969.

10. Zhou, J.Z.; Wen, X.H. Maintenance and roubleshooting of gas chromatograph. Lab. Sci. 2012, 15, $176-178$.

11. Jacob, L.; Guiochon, G. Step Increase of the Carrier Gas Inlet Pressure in Gas Chromatography. Nature 1967, 213, 491-492. [CrossRef]

12. Korolev, A.A.; Shiryaeva, V.E.; Popova, T.P.; Kurganov, A.A. Dependence of the efficiency of a capillary column in gas chromatography on the relative pressure of the carrier gas. J. Anal. Chem. 2011, 66, 184-188. [CrossRef] 
13. Korolev, A.A.; Shiryaeva, V.E.; Popova, T.P.; Kozin, A.V.; Kurganov, A.A. The influence of carrier gas pressure on the retention of sorbates on monolithic capillary columns in gas chromatography. Russ. J. Phys. Chem. 2009, 83, 670-676. [CrossRef]

14. He, Y.; Tang, L.; Wu, X.; Hou, X.; Lee, Y.I. Spectroscopy: The Best Way Toward Green Analytical Chemistry. Appl. Spectrosc. Rev. 2007, 42, 119-138. [CrossRef]

15. Benounis, M.; Aka-Ngnui, T.; Jaffrézic, N.; Dutasta, J.P. NIR and Optical fiber sensor for gases detection produced by transformation oil degradation. Sens. Actuator B 2008, 141, 76-83. [CrossRef]

16. Zhao, A.X.; Tang, X.J.; Zhang, Z.H.; Liu, J.H. The DGA interpretation method using relative content of characteristic gases and gas-ratio combinations for fault diagnosis of oil-immersed power transformers. In Proceedings of the 2014 International Symposium on Electrical Insulating Materials, Niigata, Japan, 1-5 June 2014; pp. 124-127.

17. Mao, Z.; Wen, J. Detection of dissolved gas in oil-insulated electrical apparatus by photoacoustic spectroscopy. IEEE Electr. Insul. Mag. 2015, 31, 7-14. [CrossRef]

18. Bakar, N.; Abu-Siada, A.; Islam, S. A review of dissolved gas analysis measurement and interpretation techniques. IEEE Electr. Insul. Mag. 2014, 30, 39-49. [CrossRef]

19. Skelly, D. The Transition to Next-Generation Online DGA Monitoring Technologiesilutilizing Photo-Acoustic Spectroscopy; General Electric: Boston, MA, USA, 2013.

20. Tang, X.; Li, Y.; Zhu, L.; Zhao, A.; Liu, J. On-line multi-component alkane mixture quantitative analysis using Fourier transform infrared spectrometer. Chemom. Intell. Lab. Syst. 2015, 146, 371-377. [CrossRef]

21. Sánchez, A.; Eddings, E.; Mondragón, F. Fourier Transform Infrared (FTIR) Online Monitoring of NO, N2O, and CO2 during Oxygen-Enriched Combustion of Carbonaceous Materials. Energy Fuels 2010, 24, 4849-4853. [CrossRef]

22. Liang, Y.; Tang, X.; Zhang, X.; Tian, F.; Sun, Y.; Dong, H. Portable Gas Analyzer Based on Fourier Transform Infrared Spectrometer for Patrolling and Examining Gas Exhaust. J. Spectrosc. 2015, 2015, 1-7. [CrossRef]

23. Tang, X.; Liang, Y.; Dong, H.; Sun, Y.; Luo, H. Analysis of Index Gases of Coal Spontaneous Combustion Using Fourier Transform Infrared Spectrometer. J. Spectrosc. 2014, 2014, 1-8. [CrossRef]

24. Rothman, L.S.; Gordon, I.E.; Babikov, Y.; Barbe, A.; Benner, D.C.; Bernath, P.F.; Birk, M.; Bizzocchi, L.; Boudon, V.; Brown, L.R.; et al. The HITRAN 2012 molecular spectroscopic database. J. Quant. Spectrosc. Radiat. Transf. 2013, 130, 4-50. [CrossRef]

25. Kramida, A.; Ralchenko, Y.; Reader, J.; NIST-ASD-Team. NIST Atomic Spectra Database (Version 5.2). Available online: www.nist.gov/pml/data/asd.cfm (accessed on 24 December 2017).

26. Stout, F.; Kalivas, J.H.; Héberger, K. Wavelength Selection for Multivariate Calibration Using Tikhonov Regularization. Appl. Spectrosc. 2007, 61, 85-95. [CrossRef] [PubMed]

27. Pereira, F.; Bezerra, F.; Junior, S.; Santos, J.; Chabu, I.; Souza, G.; Micerino, F.; Nabeta, S.I. Nonlinear Autoregressive Neural Network Models for Prediction of Transformer Oil-Dissolved Gas Concentrations. Energies 2018, 11, 1691. [CrossRef]

28. Bodzenta, J.; Burak, B.; Gacek, Z.; Jakubik, W.P.; Kochowski, S.; Urbańczyk, M. Thin palladium film as a sensor of hydrogen gas dissolved in transformer oil. Sens. Actuator B 2002, 87, 82-87. [CrossRef]

29. Cao, D. Gas Chromatography for Analyzing Power Transformer Oil and Approach for Fault Diagnosis; China Electric Power Press: Beijing, China, 2010.

30. Zhang, Z.; Xiao, D. A Small Vacuum On-line Extraction Technology for the Automatic Chromatographic Analysis of Gas Dissolved in Insulating Oil. Autom. Electr. Power Syst. 2007, 31, 92-96.

31. Zhao, A.; Tang, X.; Li, W.; Zhang, Z.; Liu, J. The piecewise two points auto-linear correlated correction method for Fourier transform infrared baseline wander. Spectrosc. Lett. 2015, 48, 274-279. [CrossRef]

32. IEC 60567. Oil-Filled Electrical Equipment-Sampling of Gases and Analysis of Free and Dissolved Gases-Guidance; The International Electrotechnical Commission (IEC): Geneva, Switzerland, 2011.

33. Griffiths, P.R.; de Haseth, J.A. Fourier Transform Infrared Spectrometery, 2nd ed.; Wiley: Hoboken, NJ, USA, 2007.

34. Tang, X.; Zhang, F.; Wang, W.; Tang, C.; Liang, Y.; Tian, F.; Sun, Y.; Dong, H. Identification and treatment approach for spectral baseline distortion in processing of gas analysis online by Fourier transform infrared spectroscopy. Spectrosc. Lett. 2018, 51, 134-138. [CrossRef]

35. Zhao, A.X.; Tang, X.J.; Wang, E.Z.; Zhang, Z.H.; Liu, J.H. Quantitative analysis of transformer oil dissolved gases using FTIR. Spectrosc. Spectr. Anal. 2013, 33, 2407-2410. 
36. Liu, X.; Zhou, F.; Huang, F. Research on on-line DGA using FTIR [power transformer insulation testing]. In Proceedings of the International Conference on Power System Technology, Kunming, China, 13-17 October 2002; Volume 3, pp. 1875-1880.

37. Saha, T.K. Review of modern diagnostic techniques for assessing insulation condition in aged transformers. IEEE Trans. Dielectr. Electr. Insul. 2003, 10, 903-917. [CrossRef]

38. Yao, C.; Wang, S.; Peng, G.; Li, X.; Zeng, L. A Study on the Measurement Results of Formaldehyde Emissions from SI Engine Fueled with Methanol/Gasoline Blends by FTIR and Chromatography. Automot. Eng. 2014, 7, 804-809. article distributed under the terms and conditions of the Creative Commons Attribution (CC BY) license (http:/ / creativecommons.org/licenses/by/4.0/). 